\title{
Projeto QuizTEA - Desenvolvendo Quiz Digitais para Indivíduos Portadores do Transtorno do Espectro Autista
}

\author{
Victória O. Gomes ${ }^{1}$, Ellen C. Aguiar ${ }^{1}$, Victor T. Sarinho ${ }^{1}$ \\ ${ }^{1}$ Laboratório de Entretenimento Digital Aplicado - LEnDA \\ Universidade Estadual de Feira de Santana - UEFS \\ Feira de Santana - Bahia - Brasil \\ victoria.oliveiragomes@gmail.com, chalegreaguiar@gmail.com, \\ vsarinho@uefs.br
}

\begin{abstract}
Autism Spectrum Disorder (ASD) impairs the transmission of knowledge, transforming their learning into a time-consuming and laborious process. Thus, to support the development of social aspects and the linearity of events of ASD patients, this paper presents the development of QuizTEA. It is a digital game that will be developed in digital quiz format, where, after hearing a story, the player must answer the questions in order to put in order the comics that tell the story heard.
\end{abstract}

Resumo. O Transtorno do Espectro Autista (TEA) prejudica a transmissão de conhecimento de seus portadores, transformando o aprendizado dos mesmos em um processo demorado e laborioso. Assim, para dar suporte ao desenvolvimento de aspectos sociais e da linearidade de acontecimentos de portadores do TEA, este trabalho apresenta o desenvolvimento do QuizTEA. Trata-se de jogo digital que será desenvolvido no formato de quiz digital, onde, após ouvir uma história, o jogador deverá responder as perguntas de forma a ordenar os quadrinhos que contam a história ouvida.

\section{Introdução}

O Transtorno do Espectro Autista (TEA) constitui um transtorno do neurodesenvolvimento que "acarreta em dificuldades na comunicação e interação social, e em habilidades para desenvolver, manter e compreender relacionamentos" [Martins e de Lima 2018]. Ele é um "distúrbio de desenvolvimento complexo, que é definido do ponto de vista comportamental, que apresenta etiologias múltiplas e que se caracteriza por graus variados de gravidade" [Rotta et al. 2015].

Trabalhar as características de crianças portadoras do TEA representa um desafio para seus cuidadores e professores, e interfere no ensino de novas habilidades e comportamentos [Rotta et al. 2015]. Indivíduos portadores do TEA apresentam, com frequência, deficit qualitativos na interação social e comunicação, comportamentos obsessivos e ritualísticos, como o apego à rotina rígida e a obsessão por objetos, um repertório restrito de interesses e atividades, além da dificuldade de imaginação, a qual se estende às várias áreas do pensamento.

Essas características do espectro, dentre outras, prejudicam claramente qualquer tentativa de transmissão de conhecimento [Mello 2001], tornando o aprendizado de 
crianças autistas um processo demorado e laborioso [Farias e da Cunha 2013]. Por conta dessas peculiaridades, a metodologia de ensino eficaz para portadores do TEA difere das utilizadas comumente, uma vez que é necessário, por exemplo, uma maior frequência na repetição de certas competências para promover a fixação do conteúdo, além de requerer uma maior concentração por parte da criança [Mendes 2015].

Por conta dessas peculiaridades, que devem ser levadas em conta no momento da transmissão de conteúdos para indivíduos portadores do espectro autista, jogos digitais tem se apresentado como uma alternativa aos métodos de ensino e tratamento comumente utilizados. Assim, este trabalho descreve o QuizTEA, um jogo digital que faz uso de Tecnologias da Informação e Comunicação (TICs) para trabalhar aspectos sociais e de aprendizado da linearidade de acontecimentos em indivíduos portadores do TEA. O mesmo já foi introduzido como proposta anteriormente, e seu roteiro de desenvolvimento vem sendo seguido com sucesso [Aguiar et al. 2018].

\section{Trabalhos Relacionados}

A utilização de quiz como objeto de aprendizagem em diversas áreas do conhecimento vem se mostrando muito eficaz. Ele constitui um recurso pedagógico que motiva a ação dos estudantes e auxilia no processo de aquisição de conhecimento, além de possibilitar a utilização de recursos tecnológicos [Alves et al. 2015], que por si só já garantem uma maior imersão do indivíduo na atividade.

De fato, quiz é uma estratégia clássica para a produção de jogos com propósitos, a exemplo do jogo digital Autasy [Sarinho et al. 2018] que trabalha a linearidade de acontecimentos com crianças neuroatípicas. Nele, a leitura de histórias de fantasias infantis é utilizada para questionar a criança sobre qual a ordem correta dos quadrinhos em que a história foi contada. Trata-se de um quiz que se baseia na recontação de histórias, assim como o proposto por [de Lira et al. 2009] com a história "O urubu e as pombas", onde crianças portadoras do TEA ouviam uma história e tinham a incumbência de recontá-la verbalmente.

\section{Metodologia e Resultados}

Pensando em práticas de intervenção focada [Rotta et al. 2015], QuizTEA representa uma proposta de ferramenta que busca auxiliar no desenvolvimento da compreensão da linearidade de acontecimentos em portadores do TEA, além de trabalhar, concomitantemente, aspectos de interações sociais, os quais são trazidos através das histórias. Trata-se de um quiz gráfico [Bontchev e Vassileva 2010], onde imagens são mostradas e a criança tem a missão de ordená-las de forma sequencial, de acordo com uma história infantil apresentada. Vale salientar que QuizTEA foi projetado como um quiz gráfico devido ao fato de que a comunicação por figuras é a metodologia de comunicação mais efetiva e utilizada com autistas, algo observado desde os primeiros anos de idade [Barbosa 2009].

Com relação a dinâmica do jogo, QuizTEA apresenta inicialmente a criança um áudio de uma história completa, cujo tamanho e complexidade variam de acordo com o nível em que ela se encontra. Logo em seguida é apresentado um conjunto de imagens em forma de quadrinhos, referentes a primeira cena descrita na história. O objetivo é que a criança selecione a imagem que retrate a primeira cena da história ouvida. 
Após selecionar o quadrinho que responde a pergunta feita e clicar em "Próximo", a resposta fornecida será validada. Caso esteja correta, o jogador passará para a etapa seguinte da história, onde deverá selecionar a próxima cena que se enquadra linearmente no que ela ouviu no áudio. Caso sua resposta esteja incorreta, a criança será instruída a ouvir a história novamente e fornecer uma nova resposta. Para fins de ilustração, a Figura 1 apresenta o fluxo de execução das telas do jogo em si, descrevendo a lógica de exibição do áudio e dos quizes gráficos relacionados a história contada.

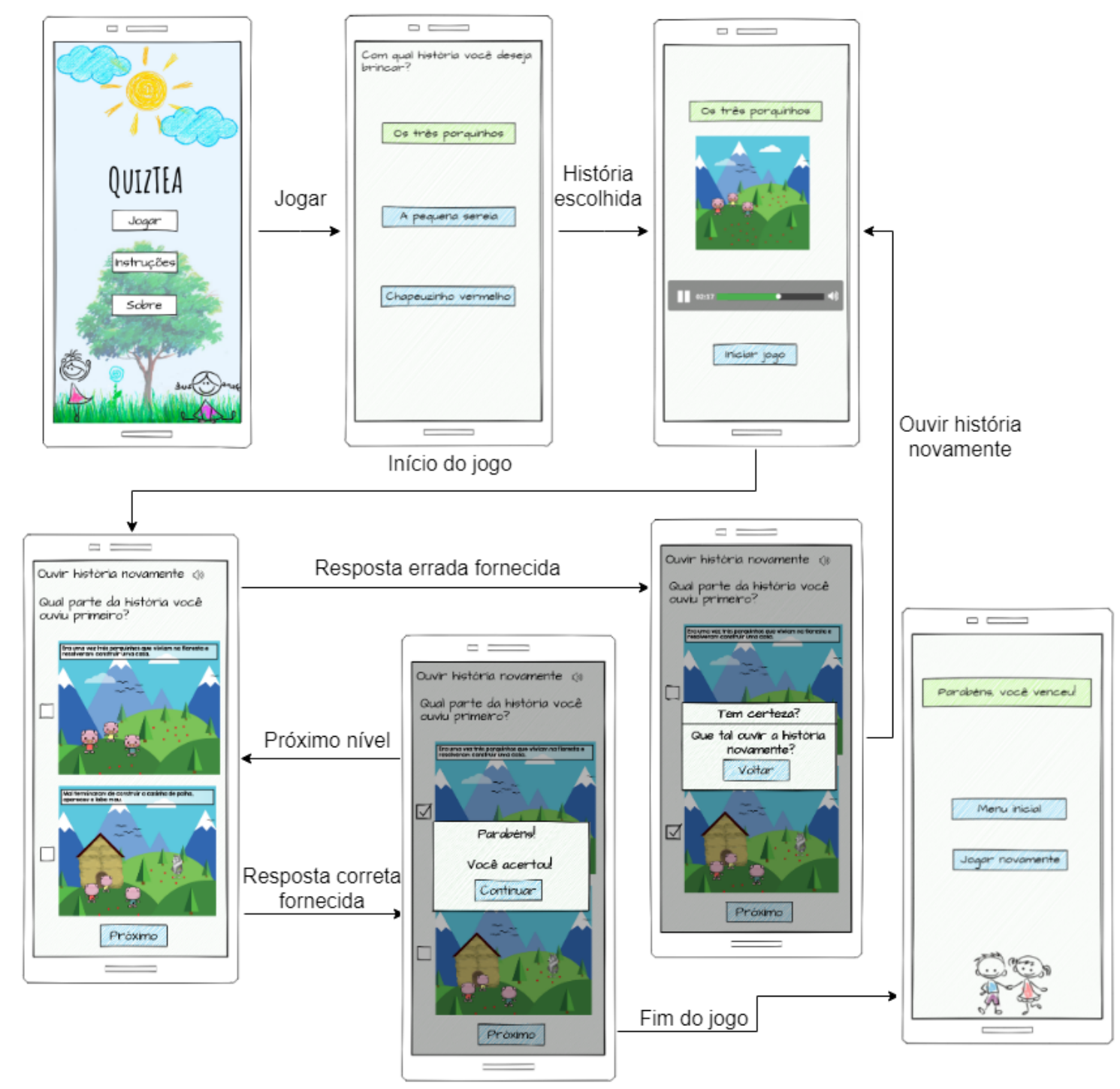

Figura 1. Fluxo de execução do QuizTEA.

No que tange as histórias utilizadas no jogo, optou-se pelo uso de áudio-livros de contos infantis, como chapeuzinho vermelho, os três porquinhos, etc. Essa escolha devese ao fato de que estes contos possuem uma linguagem de fácil entendimento, além da narrativa possuir elementos que prendem a criança na história, passando certos aprendizados importantes de maneira mais prazerosa para a mesma [Barreto et al. 2010].

Para o desenvolvimento do primeiro protótipo do jogo, foram selecionadas 3 histórias. O pequeno número se deve ao fato de que almeja-se obter uma validação do 
jogo por parte do público alvo para identificação de melhorias a serem implementadas antes do aumento do acervo de contos disponíveis. As histórias escolhidas são:

- Chapeuzinho vermelho: Mostra a interação da menina com a mãe, com o lobo, com a avó e o com o caçador ao contar a história de como ela atravessou a floresta para levar doces para a sua avó;

- A pequena sereia: Mostra a interação da sereia com a bruxa do mar, com seu pai e com o príncipe na sua busca por pernas, para poder se casar com este último;

- Os três porquinhos: Mostra a interação dos porquinhos entre si e a interação deles com o lobo em busca de construir uma casa segura para morarem.

As histórias são adaptadas e resumidas, de maneira que a duração destas varia entre 2 e 4 minutos, cada uma contando com 8 a 10 fases. A curta duração de cada história se deve a uma peculiaridade dos autistas que precisa ser considerada no desenvolvimento do jogo, que é a questão da dificuldade de estabelecer foco em uma atividade durante um período de tempo muito extenso. Para fins de ilustração, a Figura 2 apresenta a tela com o quiz gráfico referente a história dos 3 porquinhos.
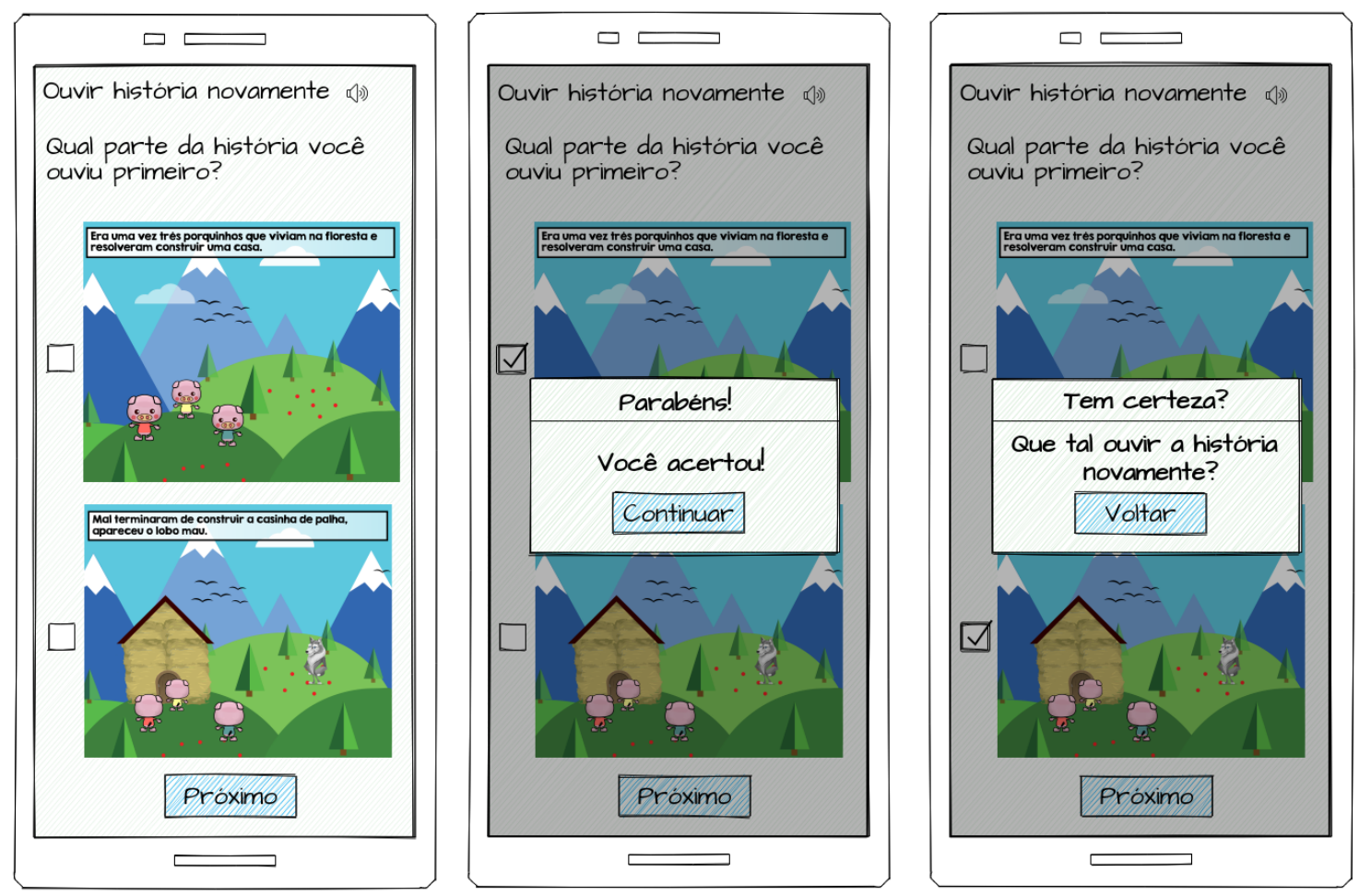

Figura 2. Representação do QuizTEA com a história dos 3 porquinhos.

\section{Conclusões e Trabalhos Futuros}

O uso de TICs com indivíduos portadores do TEA promove uma melhoria na questão da transmissão de conhecimentos para os mesmos, o que é um consenso entre os trabalhos publicados na área [Cunha 2011], apesar de haver um deficit de programas específicos voltados para estas pessoas [Barbosa 2009]. Esse uso, associado ao formato de quiz gráfico utilizado, promove a criação de uma ferramenta capaz de ser utilizada com indivíduos que estão no espectro, prendendo a atenção dos mesmos durante o jogo e, ao mesmo tempo, repassando os conhecimentos propostos. 
Assim, este trabalho apresentou a atualização do estado de desenvolvimento do QuizTEA, um jogo digital capaz de apresentar ao portador do TEA versões simplificadas de contos infantis populares, dentro de uma dinâmica que treina a linearidade de raciocínio das crianças por meio da ordenação das imagens apresentadas. Trata-se de uma ferramenta capaz de promover um aprendizado prazeroso e eficaz para o portador do transtorno, ampliando assim o leque de opções de jogos digitais capazes de serem usados no tratamento dos mesmos.

É importante salientar que utilização de tecnologias e aplicações específicas para esses indivíduos não tem por objetivo isolá-los nem afastá-los da utilização de metodologias tradicionais [Barbosa 2009]. Ela busca ser uma alternativa aos métodos comumente utilizados, pretendendo auxiliar familiares e profissionais da área.

Como trabalhos futuros, além da efetiva implementação e finalização do jogo proposto e da realização de uma avaliação da usabilidade do mesmo ao aplicá-lo em indivíduos portadores do TEA, pretende-se dispor uma maior quantidade e variedade de histórias. Isto permitiria que a criança escolha a história que deseja visualizar, de modo que a mesma se sinta mais à vontade para interagir com o jogo.

\section{Agradecimentos}

Agradecimentos ao Programa de Bolsa de Iniciação Científica da Universidade Estatual de Feira de Santana (PROBIC/UEFS) pela concessão da Bolsa de Pesquisa para este projeto.

\section{Referências}

Aguiar, E. C., Gomes, V. O., e Sarinho, V. T. (2018). QuizTEA - Uma proposta de desenvolvimento de quiz digitais para indivíduos portadores do transtorno do espectro autista. XVII Brazilian Symposium on Computer Games and Digital Entertainment (SBGames).

Alves, R., Geglio, P. C., Moita, F., Souza, C., e Araújo, M. (2015). O quiz como recurso pedagógico no processo educacional: apresentação de um objeto de aprendizagem. In XIII Congresso Internacional de Tecnologia na Educação. Pernambuco.

Barbosa, H. F. A. (2009). Análise do recurso a novas tecnologias no ensino de autistas. $\mathrm{PhD}$ thesis, Instituto Politécnico do Porto. Instituto Superior de Engenharia do Porto.

Barreto, L., Silva, N., e Melo, S. (2010). A influência dos contos infantis no desenvolvimento da linguagem infantil. Revista scientific magazine.

Bontchev, B. e Vassileva, D. (2010). Educational quiz board games for adaptive elearning. In Proc. of Int. Conf. ICTE, pages 63-70.

Cunha, R. M. (2011). Desenvolvimento e avaliação de um jogo de computador para ensino de vocabulário para crianças com autismo. Proceedings of Games for Change.

de Lira, J. O., Tamanaha, A. C., Perissinoto, J., e Osborn, E. (2009). O reconto de histórias em crianças do espectro autístico: um estudo preliminar. Revista CEFAC, 11(3):417422 . 
Farias, E. e da Cunha, M. X. C. (2013). Protótipo de uma ferramenta de software para apoio no tratamento de crianças com autismo. Simpósio Brasileiro de Sistema de Informação, João Pessoa - PB.

Martins, C. B. e de Lima, R. C. (2018). Transtorno do espectro autista. Revista Brasileira de Ciências da Vida, 6(2).

Mello, A. M. S. (2001). Autismo: guia prático. Gráfica da AMA - Associação de Amigos do Autista, doada pela Fundação Elijass Gliksmanis.

Mendes, M. A. S. (2015). A Importância da Ludicidade no Desenvolvimento de Crianças Autistas. PhD thesis, Universidade de Brasília.

Rotta, N. T., Ohlweiler, L., e dos Santos Riesgo, R. (2015). Transtornos da aprendizagem: abordagem neurobiológica e multidisciplinar. Artmed Editora.

Sarinho, V. T., Oliveira, G., e Pereira, C. P. (2018). Projeto autasy: Desenvolvendo a linearidade de acontecimentos em crianças portadoras do transtorno do espectro autista. SBGames - Games and Health Workshop. 